\title{
Resonant Converter with Voltage-Doubler Rectifier or Full-Bridge Rectifier for Wide-Output Voltage and High-Power Applications
}

\author{
Bor-Ren Lin ${ }^{1, *(\mathbb{D})}$, Guan-Hong $\operatorname{Lin}^{1}$ and Aries Jian ${ }^{2}$ \\ 1 Department of Electrical Engineering, National Yunlin University of Science and Technology, Yunlin 640, \\ Taiwan; m10612096@yuntech.edu.tw \\ 2 Mean Well Enterprises Co., Ltd., New Taipei City 24891, Taiwan; aries@meanwell.com \\ * Correspondence: linbr@yuntech.edu.tw; Tel.: +886-912312281
}

Received: 7 November 2018; Accepted: 19 December 2018; Published: 20 December 2018

\begin{abstract}
This paper presents a resonant converter with the benefits of wide output voltage, wide soft switching characteristics for power devices and high circuit efficiency. Since the series resonant circuit is adopted on the primary side, the power switches are turned on under zero voltage switching and power diodes on the secondary side can be turned off under zero current switching. To overcome the drawback of narrow voltage operation range in the conventional resonant converter, full-bridge rectifier and voltage-doubler rectifier topologies are employed on the secondary side for low-voltage output and high-voltage output applications. Therefore, the voltage rating of power devices on the secondary side is clamped at output voltage, rather than two times output voltage, in the center-tapped rectifier circuit. Synchronous power switches are used on the secondary side to further reduce the conduction losses so that the circuit efficiency can be further improved. To verify the theoretical analysis and circuit performance, a laboratory prototype with $1 \mathrm{~kW}$ rated power was built and tested.
\end{abstract}

Keywords: soft switching; resonant converter; wide output voltage

\section{Introduction}

High power density and high circuit efficiency are demanded of modern powered electronics in order to reduce the greenhouse effect. Power converters with soft switching characteristics, such as asymmetric pulse-width modulation converters [1-4] and phase-shift pulse-width modulation converters [5-8], have been developed and implemented to improve converter efficiency. The main drawback of these circuit topologies is a narrow soft switching range due to the limited energy stored on the leakage inductor under light or low load. LLC resonant converters [9-12] have the benefits of a wide soft switching range for powered devices and high efficiency. However, the narrow input and output voltage range is the main drawback of resonant converters. If a wide voltage range is needed in a series resonant converter, then a low quality factor or low inductor ratio between the magnetizing inductor and resonant inductor is usually adopted to obtain high voltage gain. Low inductor ratio will result in high circulating current loss and high conduction loss on the primary side. The circuit efficiency will be decreased. An $L L C$ resonant converter with high inductor ratio can reduce conduction loss. However, the voltage gain of resonant converter will decrease, and wide voltage range operation cannot be realized. For electric vehicle (EV) or hybrid electric vehicle (HEV) applications, the battery charging converter is built using a front-stage power factor corrector and a high-frequency link isolated dc-dc converter. For battery charging applications, the output voltage range of the dc-dc converter can be from $200 \mathrm{~V}$ to $420 \mathrm{~V}$. Therefore, high-frequency link dc-dc converters with wide output voltage are 
needed for EV and HEV applications or outdoor LED lighting systems with variable series or parallel combinations of LED strings. There are several solutions to overcome the challenges of wide input or output voltage range operation. First, the conventional full-bridge converter, as shown in Figure 1a, with wide duty cycle control can be adopted to achieve wide voltage operation. If the maximum duty cycle is four times the minimum duty cycle $\left(d_{\max }=4 d_{\min }\right)$, then the output voltage of full-bridge converter is controlled at the constant value for 4:1 input voltage range $\left(v_{\max }=4 v_{\min }\right)$. However, wide duty cycle operation will result in low circuit efficiency in cases of high input voltage and low duty cycle. The second solution to achieve wide voltage operation is using two-stage dc-dc converters, as shown in Figure 1b, such as buck or boost circuit and full-bridge circuit. Since two-stage circuits are used, the circuit efficiency is decreased and the circuit reliability is also reduced. The third solution is using single stage hybrid resonant circuit topology [12-14] as shown in Figure 1c. The wide voltage range resonant converter with full-bridge circuit $\left(S_{1} \sim S_{4}\right.$ are operation) or half-bridge $\left(S_{1}, S_{2}\right.$ and $S_{3}$ are operation) circuit topology used on the primary side $[13,14]$ has been proposed to extend the input voltage range. The main advantage of the full-bridge and half-bridge resonant converter on the primary side is the wide input voltage range $\left(v_{i n, \max }=4 v_{i n, \min }\right)$. However, there is a transient duration between the half-bridge resonant converter and the full-bridge resonant converter operation, and one power switch $S_{3}$ is always in the on-state under half-bridge resonant circuit, which will result in one more conduction loss on a powered device. The secondary side of the circuit topologies in Figure 1 is the center-tapped rectified circuit with two diodes to obtain low voltage output. If a wide output voltage is required, then diodes on the center-tapped rectifier may have a high-voltage rating problem.

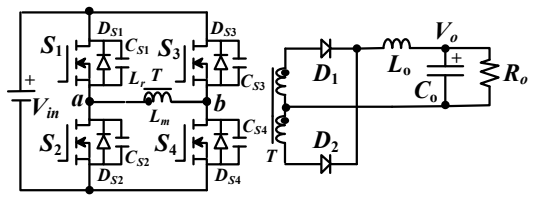

(a)

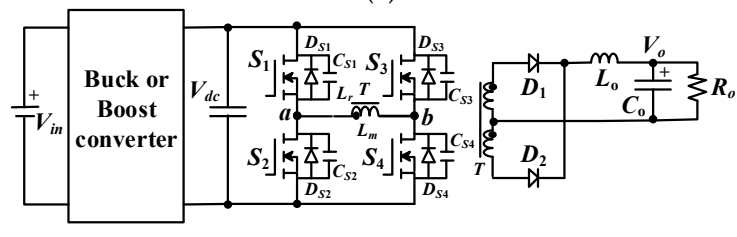

(b)

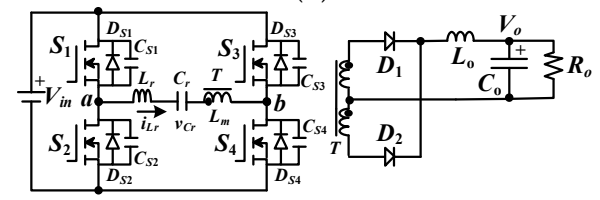

(c)

Figure 1. Circuit topologies with wide voltage operation: (a) conventional full-bridge converter; (b) two-stage converter; (c) hybrid resonant converter.

A new single-stage resonant converter is studied and presented in this paper to have the benefits of wide output voltage operation, wide soft switching characteristics, and high circuit efficiency. Due to the input inductive load characteristic of the resonant converter, all power switches on the primary side are operated under soft switching conditions. Synchronous switches are also used on the secondary side to lessen the conduction loss on power devices. To achieve wide output voltage operation, full-bridge rectifier topology or voltage-doubler rectifier topology is selected on the secondary side by using an ac power switch. For higher-voltage output, the ac power switch is turned on to realize voltage-doubler rectifier on the secondary side. On the other hand, ac power switch is turned off to realize full-bridge rectifier on the secondary side under lower voltage output. Thus, the proposed converter can achieve operation over a wide output voltage range. Compared to conventional wide input voltage operation, with full-bridge and half-bridge resonant converters on the primary side, the 
control scheme of the proposed converter is simple and easy to implement. The working principle of the circuit and the steady-state characteristics of the developed converter are provided and discussed. Finally, experiments with a $1 \mathrm{~kW}$ laboratory prototype are demonstrated to show the performance of the developed resonant converter.

\section{Circuit Diagram}

The circuit configuration of the conventional ac-dc converter for EV/HEV battery charging systems or outdoor LED lighting systems is composed of a front-stage power factor corrector and a rear-stage dc-dc converter to provide a stable wide output voltage and high power output. The front-stage power factor corrector with boost topology can achieve line current harmonics reduction and power factor correction. The second stage is the resonant converter or full-bridge converter to realize a high-efficiency circuit. However, the main drawbacks of the series resonant converter are wide frequency range and narrow input or output voltage range. The proposed $L L C$ resonant converter with wide output voltage is proposed and presented in Figure 2a. In the proposed converter, $S_{1} \sim S_{4}$ are the main power switches, $C_{r}$ and $L_{r}$ are the series resonant capacitor and inductor, $T$ is the isolation transformer, $L_{m}$ is the magnetizing inductance of transformer $T, S R_{1}$ and $S R_{2}$ are synchronous rectifiers to reduce the conduction loss on the secondary side, $D_{1}$ and $D_{2}$ are rectifier diodes, and $S_{a c}$ is the ac power switch. The full-bridge resonant converter is adopted on the primary side to provide $1 \mathrm{~kW}$ rated power. To overcome the shortcoming of narrow input or output voltage operation in the conventional LLC resonant converter, full-bridge or voltage-doubler rectifier topology is selected on the secondary side to provide wide output voltage operation for battery charger or outdoor LED lighting applications. An ac power switch $S_{a c}$ is adopted on the secondary side to achieve full-bridge rectifier topology $\left(S_{a c}\right.$ is off), as shown in Figure $2 \mathrm{~b}$ for low output voltage operation, or voltage-doubler rectifier topology $\left(S_{a c}\right.$ is on), as shown in Figure 2c for high output voltage operation. The output voltage regulation is based on the variable switching frequency to adjust the input impedance of the resonant converter and regulate the ac voltage gain of the resonant circuit. By proper selection of the inductor ratio of the magnetizing inductance, series resonant inductance and quality factor, wide output voltage operation can be realized in the proposed converter.

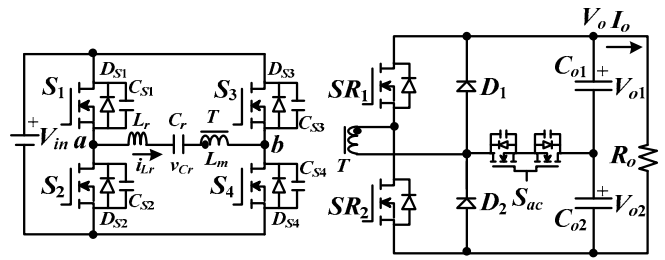

(a)

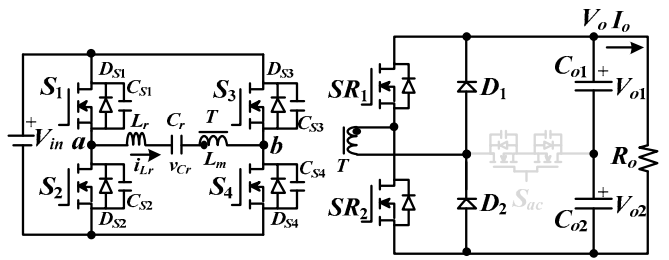

(b)

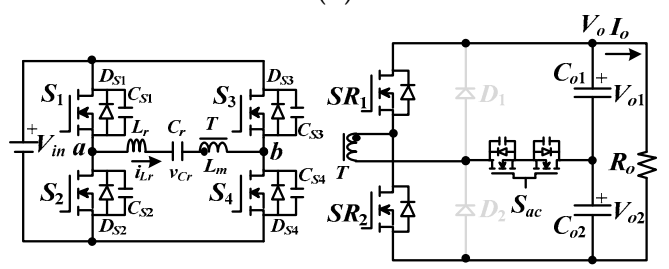

(c)

Figure 2. Proposed circuit for wide output voltage applications: (a) circuit diagram; (b) for low output voltage operation; (c) for high output voltage operation. 


\section{Operation Principle of the Proposed Converter}

The frequency modulation is employed to control load voltage and the duty ratio of each power switches on the primary side equals 0.5 . To analysis the circuit operation, the circuit components on the proposed converter are assumed as $C_{S 1}=\ldots=C_{S 4}=C_{o s s}, C_{o 1}=C_{o 2}=C_{o}$, turns ratio of $T$ is $n=N_{p} / N_{\mathrm{s}}$, and $V_{o 1}=V_{o 2}=V_{o} / 2$. Figure 3a,b illustrate the key voltage and current waveforms of the proposed converter under ac switch $S_{a c}$ is on and off, respectively. According to the switching states of $S_{1} \sim S_{4}$, $S R_{1}, S R_{2}, D_{1}, D_{2}$ and $S_{a c}$, six operation steps are observed in each switching cycle if the switching frequency is less than the series resonant frequency. Figures 4 and 5 provides the equivalent circuits in each operation step for ac switch $S_{a c}$ is on and off, respectively.

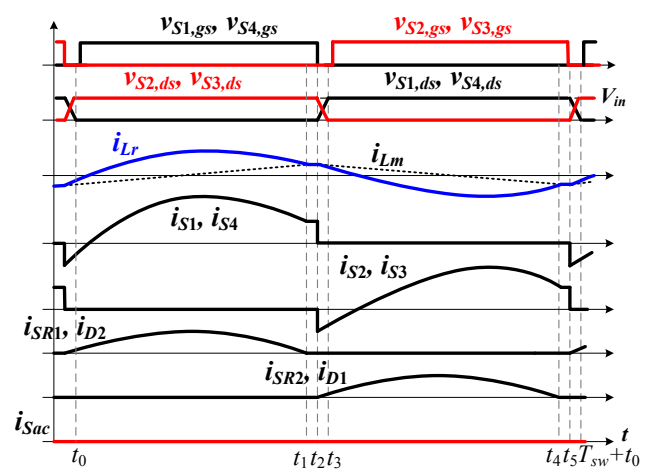

(a)

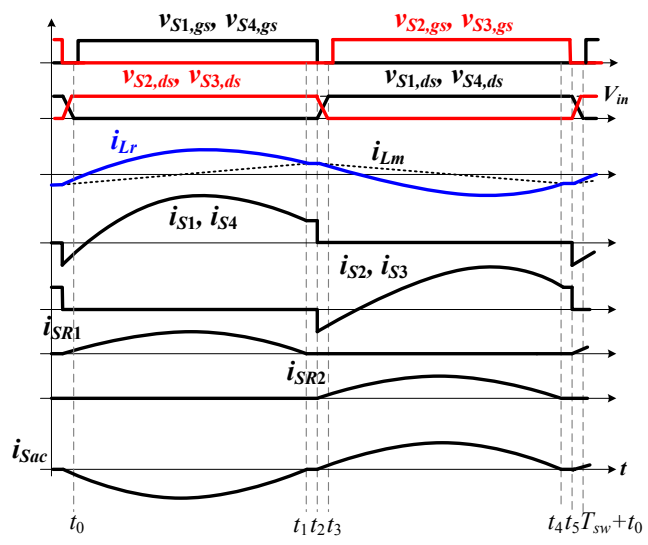

(b)

Figure 3. Pulse-width modulation waveforms of the proposed converter (a) for low output voltage operation (b) for high output voltage operation.
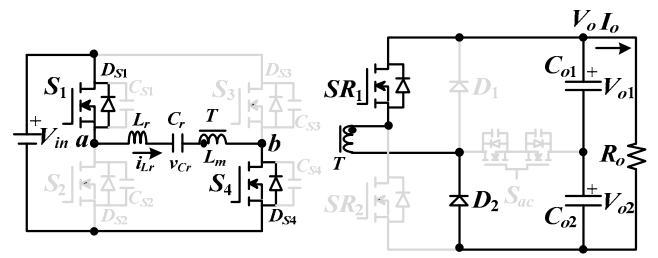

(a)

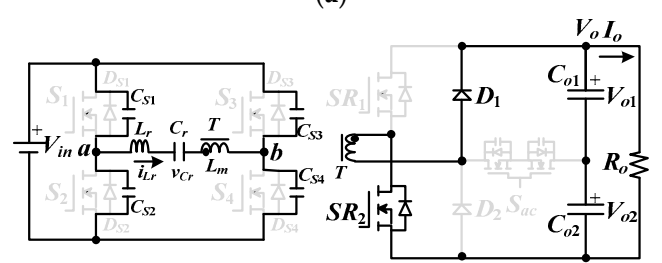

(c)
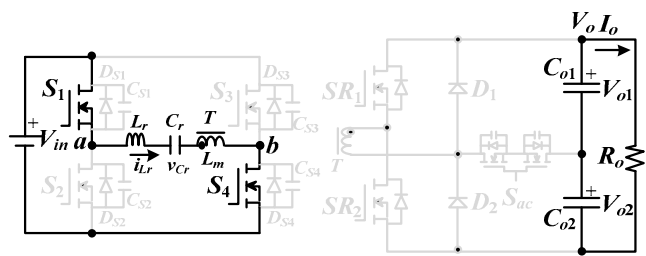

(b)
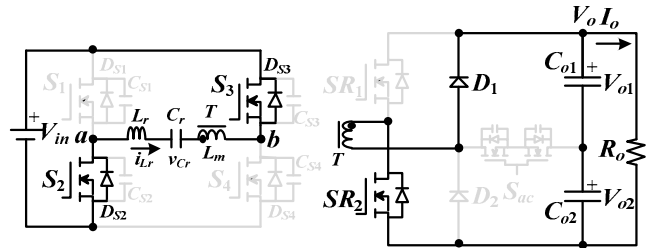

(d)

Figure 4. Cont. 

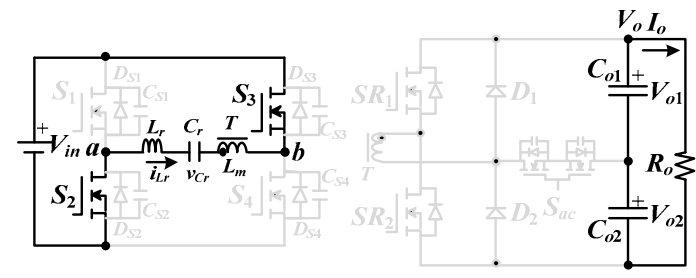

(e)

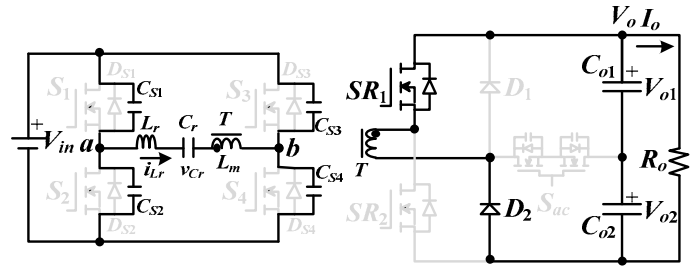

(f)

Figure 4. Equivalent circuit of the developed converter for low output voltage application (a) step 1 (b) step 2 (c) step 3 (d) step 4 (e) step 5 (f) step 6.
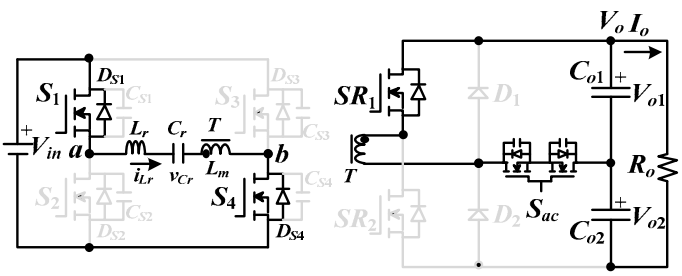

(a)

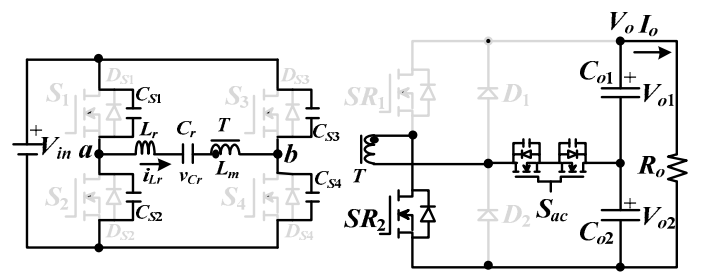

(c)
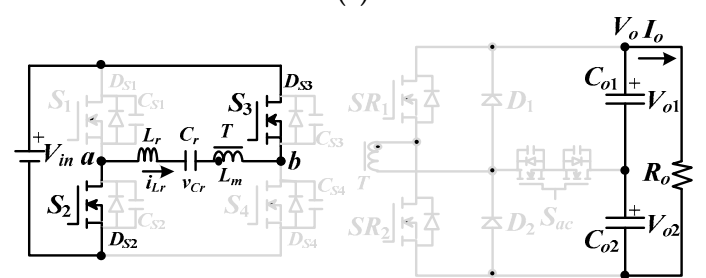

(e)
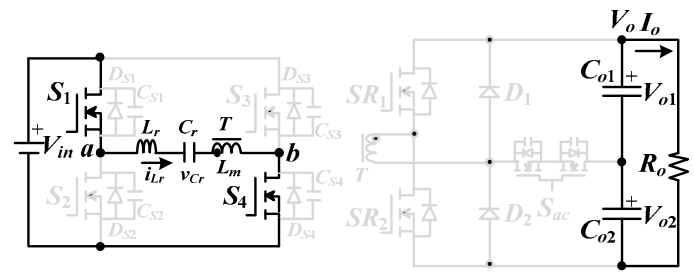

(b)
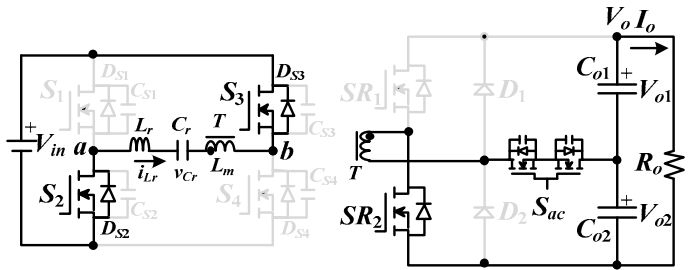

(d)

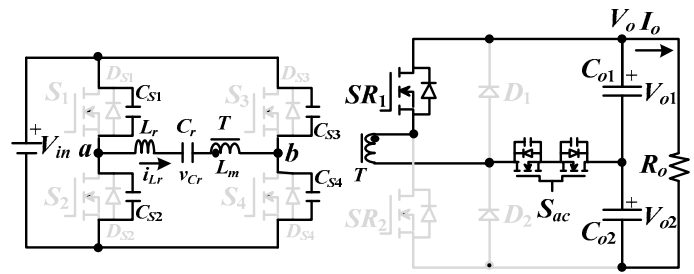

(f)

Figure 5. Equivalent circuit of the developed converter for high output voltage application (a) step 1

(b) step 2 (c) step 3 (d) step 4 (e) step 5 (f) step 6.

\subsection{For Low Output Voltage with $S_{a c}$ Off (Full-Bridge Rectifier)}

To provide low voltage output, the ac switch $S_{a c}$ is turned off, and the full-wave rectifier topology is selected on the secondary side. The circuit operation of the developed converter under low output voltage operation is discussed below.

Step $1\left[t_{0} \sim t_{1}\right]$ : Before $t_{0}$, all power switches are off. The secondary side current is positive, synchronous switch $S R_{1}$ conducts, and rectifier diode $D_{2}$ is forward biased. The output capacitors $C_{S 1}$ and $C_{S 4}$ are discharged due to the primary side current $i_{L r}$ being negative. At time $t_{0}, C_{S 1}$ and $C_{S 4}$ are discharged to zero voltage, and the body diodes $D_{S 1}$ and $D_{S 4}$ are forward biased and conduct. Then, active devices $S_{1}$ and $S_{4}$ turn on at this moment to realize zero voltage switching and reduce switching loss. The voltage $V_{i n}$ is applied to the resonant tank $L_{r}, C_{r}$ and $L_{m}$. Since $S R_{1}$ and $D_{2}$ conduct, the magnetizing voltage of $T$ is clamped at $v_{L m}=n V_{o}$. Therefore, $i_{L m}$ increases with the slope of $n V_{o} / L_{m}$. In this step, $v_{L r}$ and $i_{L r}$ are calculated by (1) and (2).

$$
v_{C r}(t)=V_{i n}-n V_{o}-\left[V_{i n}-n V_{o}-v_{C r}\left(t_{0}\right)\right] \cos \omega_{r 1}\left(t-t_{0}\right)+i_{L r}\left(t_{0}\right) Z_{r 1} \sin \omega_{r 1}\left(t-t_{0}\right)
$$




$$
i_{L r}(t)=\frac{V_{i n}-n V_{o}-v_{C r}\left(t_{0}\right)}{Z_{r 1}} \sin \omega_{r 1}\left(t-t_{0}\right)+i_{L r}\left(t_{0}\right) \cos \omega_{r 1}\left(t-t_{0}\right)
$$

where $\omega_{r 1}=1 / \sqrt{L_{r} C_{r}}$ and $Z_{r 1}=\sqrt{L_{r} / C_{r}}$. Load power is supplied from $V_{i n}$ to $V_{o}$ in this step. If half of the switching period $1 /\left(2 f_{s w}\right)$ is larger than half of the resonant period $1 /\left(2 f_{r}\right)$, then the secondary side current will decrease to zero before the end of half of the switching period. Therefore, the next circuit operation will be step 2 . Otherwise the next circuit operation will be step 3 .

Step $2\left[t_{1} \sim t_{2}\right]$ : Since $f_{s w}<f_{r}, i_{L m}$ equals $i_{L r}$ at time $t_{1}$. The rectifier diode $D_{2}$ is reverse biased, and synchronous switch $S R_{1}$ is turned off. Therefore, the primary side and secondary side of transformer $T$ are disconnected in this operating step. The components $L_{r}, C_{r}$ and $L_{m}$ are resonant, and $v_{L r}$ and $i_{L r}$ in this step are calculated by (3) and (4) with the resonant frequency $f_{r 2}=1 / 2 \pi \sqrt{\left(L_{m}+L_{r}\right) C_{r}}$.

$$
\begin{gathered}
v_{C r}(t)=V_{i n}-\left[V_{i n}-v_{C r}\left(t_{1}\right)\right] \cos \omega_{r 2}\left(t-t_{1}\right)+i_{L r}\left(t_{1}\right) Z_{r 2} \sin \omega_{r 2}\left(t-t_{1}\right) \\
i_{L r}(t)=\frac{V_{i n}-v_{C r}\left(t_{1}\right)}{Z_{r 2}} \sin \omega_{r 2}\left(t-t_{1}\right)+i_{L r}\left(t_{1}\right) \cos \omega_{r 2}\left(t-t_{1}\right)
\end{gathered}
$$

Step $3\left[t_{2} \sim t_{3}\right]$ : Active devices $S_{1}$ and $S_{4}$ turn off at time $t_{2}$. Since $i_{L r}\left(t_{2}\right)>0, C_{S 2}$ and $C_{S 3}$ are discharged and $C_{S 1}$ and $C_{S 4}$ are charged in this operating step. The secondary side current becomes negative, such that $S R_{2}$ is forced to turn on in order to reduce the conduction loss, and diode $D_{1}$ is forward biased. The magnetizing voltage $v_{L m}=-n V_{o}$ and $i_{L m}$ decreases. If the peak magnetizing current at $t_{2}$ is large enough, $C_{S 2}$ and $C_{S 3}$ can be discharged to zero voltage at time $t_{3}$.

$$
v_{C S 2}(t)=v_{C S 3}(t)=V_{\text {in }}-\frac{i_{L r}\left(t_{2}\right)}{2 C_{\text {oss }}}\left(t-t_{2}\right) \approx V_{\text {in }}-\frac{\Delta i_{L m}}{4 C_{\text {oss }}}\left(t-t_{2}\right)
$$

Step $4\left[t_{3} \sim t_{4}\right]$ : At time $t_{3}, v_{C S 2}\left(t_{3}\right)=v_{C S 3}\left(t_{3}\right)=0$. Since $i_{L r}\left(t_{3}\right)>0$, the body diodes $D_{S 2}$ and $D_{S 3}$ are forward biased. Therefore, active devices $S_{2}$ and $S_{3}$ turn on at this moment to achieve zero voltage switching and reduce the switching loss. The secondary side components $S R_{2}$ and $D_{1}$ conduct so that $v_{L m}=-n V_{o} / 2$ and $i_{L m}$ decreases. $L_{r}$ and $C_{r}$ are resonant with the applied voltage $n V_{o}-V_{i n}$, and $v_{L r}$ and $i_{L r}$ in this operating step are calculated as:

$$
\begin{gathered}
v_{C r}(t)=n V_{o}-V_{i n}-\left[n V_{o}-V_{i n}-v_{C r}\left(t_{3}\right)\right] \cos \omega_{r 1}\left(t-t_{3}\right)+i_{L r}\left(t_{3}\right) Z_{r 1} \sin \omega_{r 1}\left(t-t_{3}\right) \\
i_{L r}(t)=\frac{n V_{o}-V_{i n}-v_{C r}\left(t_{3}\right)}{Z_{r 1}} \sin \omega_{r 1}\left(t-t_{3}\right)+i_{L r}\left(t_{3}\right) \cos \omega_{r 1}\left(t-t_{3}\right)
\end{gathered}
$$

If $1 /\left(2 f_{s w}\right)>1 /\left(2 f_{r}\right)$, then the secondary side current will decrease to zero before the end of half of the switching period. Therefore, the next circuit operation will be step 5 . Otherwise the next circuit operation will be step 6 .

Step 5 [ $t_{4} \sim t_{5}$ ]: Because $f_{s w} / 2<f_{r} / 2, i_{L m}=i_{L r}$ at time $t_{4}$ and $D_{1}$ becomes reverse biased, and synchronous switch $S R_{2}$ turns off. $L_{r}, C_{r}$ and $L_{m}$ are resonant with frequency $f_{r 2}=1 / 2 \pi \sqrt{\left(L_{m}+L_{r}\right) C_{r}}$ in step 5 . The voltage $v_{L r}$ and current $i_{L r}$ are obtained as:

$$
\begin{gathered}
v_{C r}(t)=-V_{i n}+\left[V_{i n}+v_{C r}\left(t_{4}\right)\right] \cos \omega_{r 2}\left(t-t_{4}\right)+i_{L r}\left(t_{4}\right) Z_{r 2} \sin \omega_{r 2}\left(t-t_{4}\right) \\
i_{L r}(t)=-\frac{V_{i n}+v_{C r}\left(t_{4}\right)}{Z_{r 2}} \sin \omega_{r 2}\left(t-t_{4}\right)+i_{L r}\left(t_{4}\right) \cos \omega_{r 2}\left(t-t_{4}\right)
\end{gathered}
$$

Step $6\left[t_{5} \sim T_{s w}+t_{0}\right]$ : Powered devices $S_{2}$ and $S_{3}$ turn off at time $t_{5}$. Due to the secondary side current being positive, $D_{2}$ becomes forward biased and $S R_{1}$ is turned on to reduce the conduction loss on the secondary side. Due to $i_{L r}\left(t_{5}\right)<0, C_{S 1}$ and $C_{S 4}$ are discharged. If the peak magnetizing current at $t_{5}$ is large enough, $C_{S 1}$ and $C_{S 4}$ can be discharged to zero voltage. 


$$
v_{C S 1}(t)=v_{C S 4}(t)=V_{i n}+\frac{i_{L r}\left(t_{5}\right)}{2 C_{\text {oss }}}\left(t-t_{5}\right) \approx V_{\text {in }}-\frac{\Delta i_{L m}}{4 C_{\text {oss }}}\left(t-t_{5}\right)
$$

At $T_{S w}+t_{0}, C_{S 1}$ and $C_{S 4}$ are discharged to zero voltage. Then, the body diodes $D_{S 1}$ and $D_{S 4}$ are forward biased and the circuit operation for next switching period begins from time $T_{s w}+t_{0}$.

\subsection{For High Output Voltage with $S_{a c}$ on (Voltage Double Rectifier)}

When the ac switch $S_{a c}$ is turned on, as shown in Figure 2c, the secondary side circuit topology of the proposed converter is a voltage-doubler rectifier to provide high output voltage. The circuit operation with the voltage-doubler rectifier topology on the secondary side is discussed below.

Step 1 [ $t_{0} \sim t_{1}$ ]: Before time $t_{0}, S_{1} \sim S_{4}$ are off. Due to the secondary side current being positive, synchronous switch $S R_{1}$ and switch $S_{a c}$ are conducting. Since $i_{L r}<0$ before time $t_{0}, C_{S 1}$ and $C_{S 4}$ are discharged. $C_{S 1}$ and $C_{S 4}$ are discharged to zero voltage at time $t_{0}$. Then, the body diodes $D_{S 1}$ and $D_{S 4}$ conduct. Therefore, $S_{1}$ and $S_{4}$ can be turned on at $t_{0}$ to accomplish zero voltage switching. Input voltage $V_{i n}$ is connected to the resonant tank $L_{r}, C_{r}$ and $L_{m}$. Due to $v_{L m}=n V_{o 1}=n V_{o} / 2, i_{L m}$ increases with the slope of $n V_{o 1} / L_{m}$. In step 1, the voltage $v_{L r}$ and current $i_{L r}$ on the primary side are obtained as:

$$
\begin{gathered}
v_{C r}(t)=V_{i n}-n V_{o} / 2-\left[V_{i n}-n V_{o} / 2-v_{C r}\left(t_{0}\right)\right] \cos \omega_{r 1}\left(t-t_{0}\right)+i_{L r}\left(t_{0}\right) Z_{r 1} \sin \omega_{r 1}\left(t-t_{0}\right) \\
i_{L r}(t)=\frac{V_{i n}-n V_{o} / 2-v_{C r}\left(t_{0}\right)}{Z_{r 1}} \sin \omega_{r 1}\left(t-t_{0}\right)+i_{L r}\left(t_{0}\right) \cos \omega_{r 1}\left(t-t_{0}\right)
\end{gathered}
$$

If $1 /\left(2 f_{s w}\right)>1 /\left(2 f_{r}\right)$, then the next circuit operation goes to step 2 . Otherwise the next circuit operation will go to step 3 .

Step $2\left[t_{1} \sim t_{2}\right]$ : Since $f_{s w}<f_{r}, i_{L m}$ will equal $i_{L r}$ at $t_{1}$ and the secondary side current equals zero. Then, the synchronous switch $S R_{1}$ turns off. In the operating step 2, the primary side and secondary side of transformer $T$ is disconnected. Therefore, $L_{r}, C_{r}$ and $L_{m}$ are resonant with frequency $f_{r 2}=1 / 2 \pi \sqrt{\left(L_{m}+L_{r}\right) C_{r}}$. The primary side voltage $v_{L r}$ and current $i_{L r}$ are derived the same as in (3) and (4). If the $f_{s w}$ is close to $f_{r}$, the current variation $\Delta i_{L m}$ on the magnetizing inductor $L_{m}$ in steps 1 and 2 (about half of the switching period $T_{s w} / 2$ ) is approximately expressed by (13).

$$
\Delta i_{L m}(t) \approx \frac{n V_{o}}{4 L_{m} f_{s w}}
$$

Step $3\left[t_{2} \sim t_{3}\right]$ : At time $t_{2}, S_{1}$ and $S_{4}$ turn off. Due to $i_{L r}\left(t_{2}\right)$ being positive, $C_{S 2}$ and $C_{S 3}$ are discharged in this operating step. The secondary side current is negative, and $S R_{2}$ turns on to reduce the conduction loss. The magnetizing voltage $v_{L m}=-n V_{o 2}=-n V_{o} / 2$ and $i_{L m}$ decreases. If the peak magnetizing current $\Delta i_{L m} / 2$ at time $t_{2}$ is large enough, then $C_{S 2}$ and $C_{S 3}$ can be discharged to zero voltage at time $t_{3}$. The voltages on $C_{S 2}$ and $C_{S 3}$ can be approximately expressed as:

$$
v_{C S 2}(t)=v_{C S 3}(t) \approx V_{i n}-\frac{n V_{o}}{16 L_{m} C_{o s s} f_{s w}}\left(t-t_{2}\right)
$$

Step $4\left[t_{3} \sim t_{4}\right]$ : The capacitors $C_{S 2}$ and $C_{S 3}$ are discharged to zero voltage at time $t_{3}$ due to $i_{L r}\left(t_{3}\right)$ being positive. Then $D_{S 2}$ and $D_{S 3}$ become forward biased, and $S_{2}$ and $S_{3}$ can be turned on after $t_{3}$ to accomplish soft switching operation. On the secondary side, $S R_{2}$ and $S_{a c}$ are conducting, so that $v_{L m}=-n V_{o 2}=-n V_{o} / 2$ and $i_{L m}$ declines. In step $4, L_{r}$ and $C_{r}$ are resonant with the applied voltage $n V_{o} / 2-V_{i n}$. The primary voltage $v_{L r}$ and current $i_{L r}$ are obtained as:

$$
v_{C r}(t)=n V_{o} / 2-V_{i n}-\left[n V_{o} / 2-V_{i n}-v_{C r}\left(t_{3}\right)\right] \cos \omega_{r 1}\left(t-t_{3}\right)+i_{L r}\left(t_{3}\right) Z_{r 1} \sin \omega_{r 1}\left(t-t_{3}\right)
$$




$$
i_{L r}(t)=\frac{n V_{o} / 2-V_{i n}-v_{C r}\left(t_{3}\right)}{Z_{r 1}} \sin \omega_{r 1}\left(t-t_{3}\right)+i_{L r}\left(t_{3}\right) \cos \omega_{r 1}\left(t-t_{3}\right)
$$

If $f_{s w}<f_{r}$, then the secondary side current will decline to zero at $t_{4}$ and the next operation step goes to step 5. Otherwise the next operating step goes to step 6 .

Step 5 [ $t_{4} \sim t_{5}$ ]: Since $f_{s w}<f_{r}$, the magnetizing current $i_{L m}$ will decline and be equal to $i_{L r}$ at time $t_{4}$. Then, the synchronous switch $S R_{2}$ will be forced to turn off. On the primary side, the components $L_{r}$, $C_{r}$ and $L_{m}$ are resonant with frequency $f_{r 2}=1 / 2 \pi \sqrt{\left(L_{m}+L_{r}\right) C_{r}}$. If the $f_{s w}$ is close to $f_{r}$, the current variation $\Delta i_{L m}$ on $L_{m}$ in Steps 4 and 5 is the same as in (13).

Step 6 [ $\left.t_{5} \sim T_{s w}+t_{0}\right]: S_{2}$ and $S_{3}$ are turned off at $t_{5}$. Since the secondary side current becomes positive, $S R_{1}$ turns on to charge capacitor $C_{o 1}$. The current $i_{L r}\left(t_{5}\right)<0$ will discharge $C_{S 1}$ and $C_{S 4}$. At time $T_{S w}$ $+t_{0}, C_{S 1}$ and $C_{S 4}$ are discharged to zero voltage. Then, the body diodes $D_{S 1}$ and $D_{S 4}$ of $S_{1}$ and $S_{4}$ become forward biased, and the circuit operations in a switching cycle are finished.

\section{Circuit Characteristics and Design Considerations}

For general $L L C$ resonant converters, a variable frequency control is normally adopted to regulate output voltage against input voltage variation and load current change. The duty cycle of each switch is close to 0.5 , with a small dead time between the complementary switches in the same leg to allow zero-voltage switching. Fundamental frequency analysis is normally adopted to obtain the approximate voltage gain of the $L L C$ resonant converter. Due to the low output voltage ( $S_{a c}$ is off as shown in Figure $2 b)$ or high output voltage $\left(S_{a c}\right.$ is on as shown in Figure $\left.2 c\right)$, the fundamental frequency equivalent circuit of the proposed converter is provided in Figure 6a. The fundamental root mean square voltages at input and output terminals of the equivalent circuit are obtained in (17).

$$
V_{i n, a c}=2 \sqrt{2} V_{i n} / \pi, V_{L m, a c}=2 \sqrt{2} n V_{o} / \pi \text { (if } S_{a c} \text { off), or } \sqrt{2} n V_{o} / \pi \text { (if } S_{a c} \text { on) }
$$

The load resistance $R_{o}$ reflected to the primary side of transformer is calculated as

$$
R_{a c}=\frac{8 n^{2}}{\pi^{2}} R_{o}\left(\text { if } S_{a c} \text { off }\right), \text { or } \frac{2 n^{2}}{\pi^{2}} R_{o}\left(\text { if } S_{a c} \text { on }\right)
$$

Therefore, the ac voltage gain of the resonant tank shown in Figure 6a is calculated as

$$
\begin{gathered}
\left|G_{S a c, o n}\right|=\frac{n V_{o}}{V_{\text {in }}}=\frac{2}{\sqrt{\left[1+\frac{1}{L_{n}}\left(1-\frac{1}{F^{2}}\right)\right]^{2}+Q^{2}\left(F-\frac{1}{F}\right)^{2}}} \\
\left|G_{S a c, o f f}\right|=\frac{n V_{o}}{V_{\text {in }}}=\frac{1}{\sqrt{\left[1+\frac{1}{L_{n}}\left(1-\frac{1}{F^{2}}\right)\right]^{2}+Q^{2}\left(F-\frac{1}{F}\right)^{2}}}
\end{gathered}
$$

where the quality factor $Q=\sqrt{L_{r} / C_{r}} / R_{a c}$, inductor ratio $L_{n}=L_{m} / L_{r}$, series resonant frequency $f_{r 1}=1 / 2 \pi \sqrt{L_{r} C_{r}}$ and frequency ratio $F=f_{s w} / f_{r 1}$. Figure $6 \mathrm{~b}$ gives the gain curve of the $L L C$ resonant converter based on the different quality factor $Q$ and frequency ratio $F$ under the inductor ratio $L_{n}=5$. If the circuit is operated on the negative slope of the constant quality factor $Q$ characteristics, power switches are operated at inductive load and zero-voltage switching is realized. It can be observed from Figure $6 \mathrm{~b}$ that the core loss of magnetic components increases if the switching frequency increases. On the other hand, the circulating current loss increases if the switching frequency decreases. A lower quality factor $Q$ obtains a higher voltage gain $G$. A lower output voltage or higher input voltage will result in a lower dc voltage gain and the switching frequency increases. Similarly, a higher output voltage or lower input voltage will obtain a higher dc voltage gain and the switching frequency decreases. 


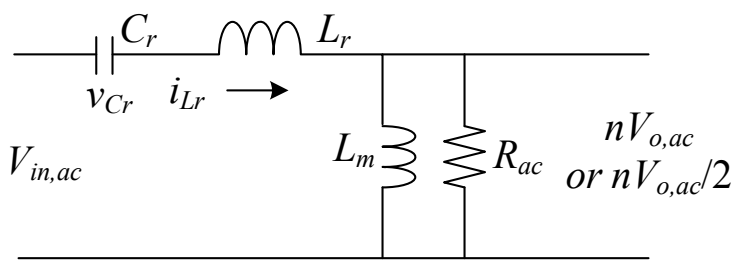

(a)

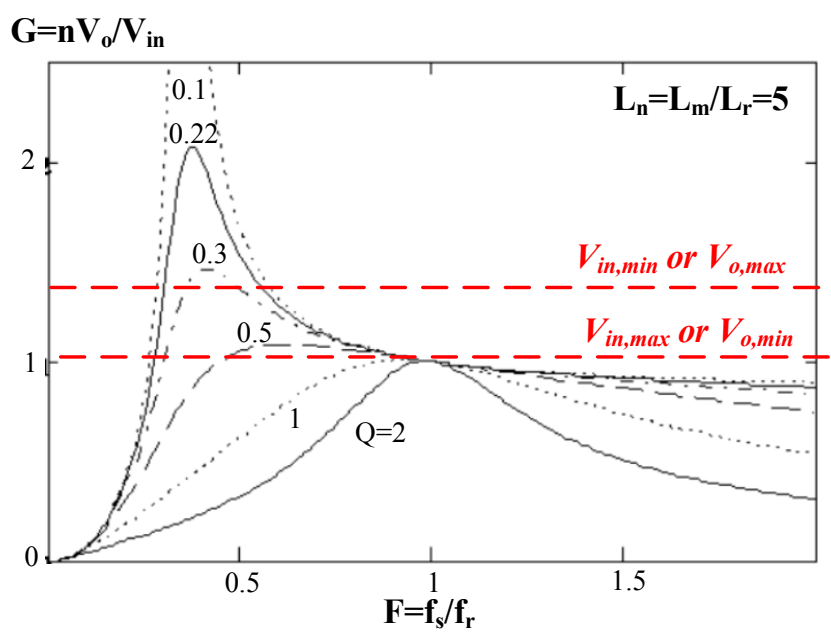

(b)

Figure 6. Resonant converter: (a) ac equivalent circuit of the resonant tank; (b) ac voltage gain curve versus normalized switching frequency.

The proposed converter was built and tested as a laboratory prototype with the following electrical specifications: $V_{\text {in }}=400 \mathrm{~V}, V_{o}=360 \mathrm{~V} \sim 120 \mathrm{~V}(3: 1), P_{\text {orated }}=1000 \mathrm{~W}$, and $f_{r 1}=100 \mathrm{kHz}$. To realize wide output voltage operation (3:1), a low inductor ratio $L_{n}$ and low quality factor $Q$ at full load are needed to achieve wider voltage gain. However, the low $L_{n}$ and $Q$ will result in the serious circulating current losses on powered devices and magnetic windings, decreasing the circuit efficiency. Therefore, ac power switch $S_{a c}$ is adopted on the secondary side to select full-bridge rectifier topology or voltage double rectifier topology for low output voltage application or high output voltage application. Thus, the reasonable inductor ratio $L_{n}$ and quality factor $Q$ can be adopted in the proposed converter to keep the high circuit efficiency benefit of the resonant converter. Since the output voltage with voltage-doubler rectifier topology is two times that of the output voltage with full-bridge rectifier topology, the prototype $L L C$ resonant converter is designed for 4:1 wide output voltage range from $480 \mathrm{~V}$ to $120 \mathrm{~V}$ output. Although the actual output voltage range is from $360 \mathrm{~V}$ to $120 \mathrm{~V}$ in the laboratory prototype, the wide output voltage range in this circuit design will give more operation range considered for some proper voltage tolerance. Figure 6 shows typical voltage gain curves of proposed converter with $4: 1$ output voltage range from $120 \mathrm{~V}$ to $480 \mathrm{~V}$ at $V_{\text {in }}=400 \mathrm{~V}$ condition. The transient voltage, $V_{o, \text { tran }}$, between full-bridge rectifier topology and voltage-doubler rectifier topology selection is designed to be $240 \mathrm{~V}$, with $\pm 5 \mathrm{~V}$ voltage tolerance using a Schmitt trigger comparator. Therefore, the LLC resonant converter with full-bridge rectifier is adopted if the output voltage range is from $120 \mathrm{~V}$ to $240 \mathrm{~V}$. On the other hand, the $L L C$ resonant converter with voltage-doubler rectifier is employed if the output voltage range is from $240 \mathrm{~V}$ to $480 \mathrm{~V}$. In this way, the design considerations for both full-bridge rectifier and voltage-doubler rectifier are identical due to $V_{o, \text { voltage-doubler rectifier }}=2 V_{o, \text { full-bridge rectifier }}$ under the same operation condition. For full-bridge rectifier topology on the secondary side of the proposed converter 
with $S_{a c}$ off, the minimum voltage gain $G_{S a c, o f f, \text { min }}$ is designed at unity under $V_{o, \min }=120 \mathrm{~V}$ condition. The theoretical turn ratio $n$ of transformer $T$ is calculated in (21).

$$
n=\frac{G_{S a c, o f f, \min } V_{i n}}{V_{o, \min }}=\frac{1 \times 400}{120}=3.333
$$

Magnetic core EER-42 core is used to implement transformer $T$ with flux density $\Delta B=0.5 T$ and $A_{e}=2.4 \mathrm{~cm}^{2}$. It is assumed that the minimum switching frequency is $60 \mathrm{kHz}$ at $V_{o, t r a n}$. Then, the minimum winding turns is calculated as:

$$
N_{p, \text { min }} \geq \frac{n V_{o, \text { tran }}}{2 f_{s, \text { min }} \Delta B A_{e}}=\frac{3.333 \times 240}{2 \times 60,000 \times 0.5 \times 2.4 \times 10^{-4}} \approx 56
$$

The actual primary turns and secondary turns are $N_{p}=57$ turns and $N_{s}=17$ turns. The ac equivalent resistance $R_{a c}$ at the rated power and minimum output voltage $120 \mathrm{~V}$ is obtained as:

$$
R_{a c}=\frac{8 n^{2}}{\pi^{2}} R_{o, \text { rated }}=\frac{8 \times(57 / 17)^{2}}{\pi^{2}} \times \frac{120^{2}}{1000} \approx 131.2 \Omega
$$

The inductor ratio $L_{n}$ is set as 5 . The voltage gain curves of the proposed converter with different quality factor $Q$ and frequency ratio $F$ under full-bridge rectifier ( $S_{a c}$ off) and voltage-doubler rectifier $\left(S_{a c}\right.$ off) are illustrated in Figure 7.

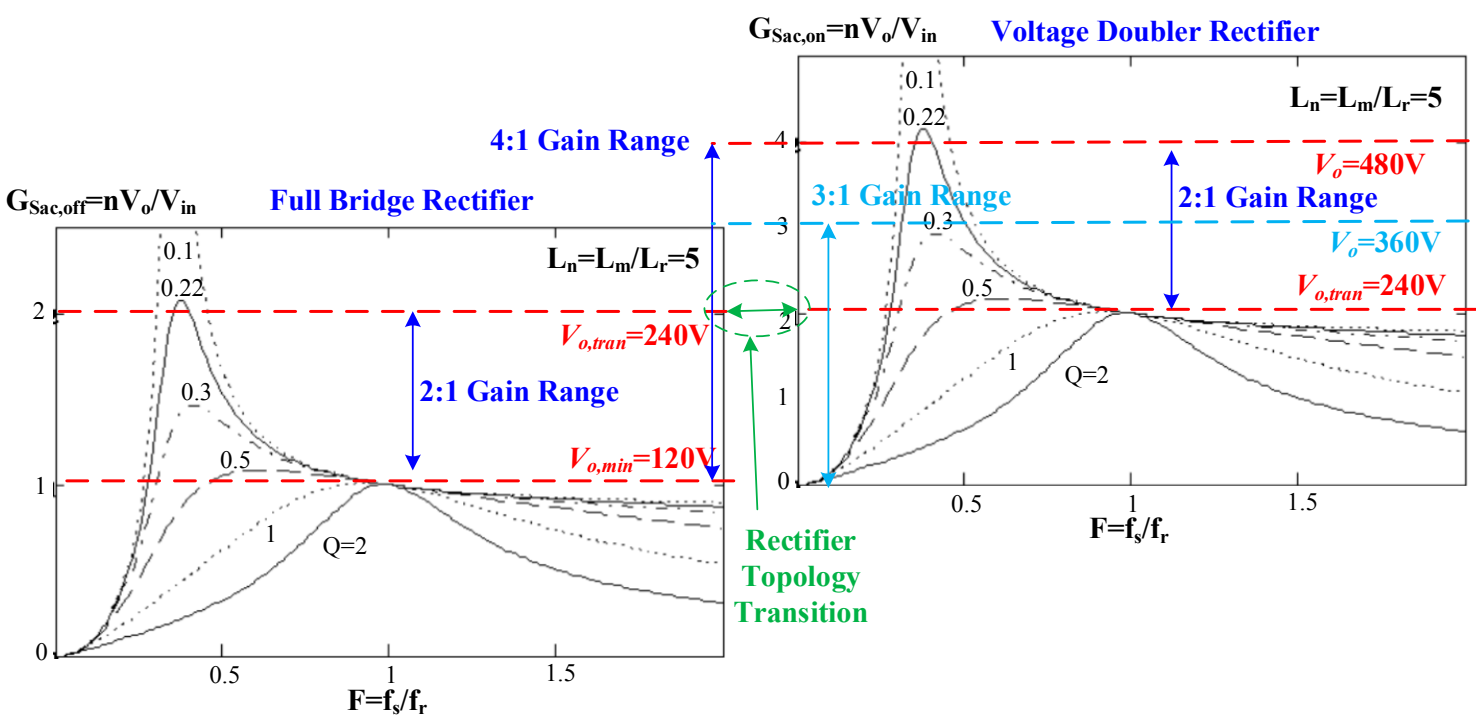

Figure 7. Typical voltage gain curves of proposed converter with 4:1 output voltage range from $V_{o, \min }=120 \mathrm{~V}$ to $V_{o, \max }=480 \mathrm{~V}$ at $V_{\text {in }}=400 \mathrm{~V}$.

Based on the gain curves in Figure 7, it is observed that the output voltage can be controlled well if the $Q=0.22$ at full load is selected. Because $Q=0.22, L_{n}=5$ and $f_{r 1}=100 \mathrm{kHz}, L_{r}, L_{m}$ and $C_{r}$ are calculated as:

$$
\begin{gathered}
L_{r}=\frac{Q R_{a c}}{2 \pi f_{r 1}}=\frac{0.22 \times 131.2}{2 \pi \times 100,000} \approx 46 \mu \mathrm{H} \\
L_{m}=L_{r 1} L_{n}=46 \times 5=230 \mu \mathrm{H} \\
C_{r}=\frac{1}{4 \pi^{2} L_{r} f_{r 1}^{2}}=\frac{1}{4 \pi^{2} \times 46 \times 10^{-6} \times(100,000)^{2}} \approx 55 \mathrm{nF}
\end{gathered}
$$


The theoretical root mean square current of $C_{r}$ and $L_{r}$ is calculated as:

$$
i_{C r, r m s}=i_{L r, r m s}=\sqrt{\left(\frac{\pi I_{o, \max }}{2 \sqrt{2} n}\right)^{2}+\left(\frac{n V_{o}}{4 \sqrt{3} L_{m} f_{s, \min }}\right)^{2}}=\sqrt{\left(\frac{\pi \times(1000 / 120)}{2 \times \sqrt{2} \times 57 / 17}\right)^{2}+\left(\frac{(57 / 17) \times 120}{4 \sqrt{3} \times 230 \times 10^{-6} \times 60,000}\right)^{2}} \approx 5 \mathrm{~A}
$$

The voltage rating of $C_{r}$ is calculated as:

$$
v_{C r, \text { rating }}=\sqrt{2} i_{C r, r m s} /\left(2 \pi f_{s, \min } C_{r}\right) \approx 341 \mathrm{~V}
$$

The theoretical voltage rating of the power switches and diodes is obtained as:

$$
\begin{gathered}
v_{S 1, \text { rating }}=\ldots=v_{S 4, \text { rating }}=V_{\text {in }}=400 \mathrm{~V} \\
v_{\text {Sac,rating }}=V_{o, \text { tran }} / 2=120 \mathrm{~V} \\
v_{S R 1, \text { rating }}=v_{S R 2 \text {,rating }}=V_{o, \max }=360 \mathrm{~V} \\
v_{D 1, \text { rating }}=v_{D 2, \text { rating }}=V_{o, \text { tran }}=240 \mathrm{~V}
\end{gathered}
$$

The diodes STTH12R06 with $600 \mathrm{~V} / 12$ A rating are used for the secondary side diodes $D_{1}$ and $D_{2}$. The MOSFETs FMW60N099S2H with $600 \mathrm{~V} / 24 \mathrm{~A}$ rating are used for all power switches in the proposed circuit. Frequency control integrated analog circuit UCC25600 is used to control power switches $S_{1} \sim S_{4}$. The synchronous switches $S R_{1}$ and $S R_{2}$ are controlled with the integrated analog circuit MP6922. The output capacitances of $C_{1}$ and $C_{2}$ are $470 \mu \mathrm{F} / 400 \mathrm{~V}$.

\section{Experimental Results}

A $1 \mathrm{~kW}$ laboratory prototype with the circuit parameters derived in the previous section was built and tested to demonstrate the performance and verify the effectiveness of the developed converter for wide output voltage applications such as outdoor LED lighting. The pictures of the laboratory prototype circuit and control board are provided in Figure 8. Figure 9 shows the simulated waveforms of the proposed converter operated at the rated power under minimum and maximum output voltages. For low voltage output $V_{o}=120 \mathrm{~V}$, the ac switch $S_{a c}$ is off and the secondary side circuit is a full-bridge rectifier. For high voltage output $V_{o}=360 \mathrm{~V}$, the ac switch $S_{a c}$ conducts and the secondary side circuit is a voltage-doubler rectifier. Therefore, the diode currents $i_{D 1}=i_{D 2}=0$. Figure 10 illustrates the experimental waveforms of the proposed converter under $120 \mathrm{~V}$ voltage output and the rated power $1 \mathrm{~kW}$. Since the full waveform rectifier is adopted on the secondary side for $V_{o}=120 \mathrm{~V}$ output, the ac switch $S_{a c}$ is open. The secondary side current flows through $S R 1, S R 2, D 1$ and $D 2$. Figure 10a shows the measured results of the primary side waveforms $i_{L r}, v_{C r}$ and $v_{a b}$ under the rated power. The switching frequency is closed to the series resonant frequency $100 \mathrm{kHz}$ and the primary side current is approximately sinusoidal waveforms. The measured secondary side currents $i_{S R 1}, i_{S R 2}, i_{D 1}$ and $i_{D 2}$ under the rated power are demonstrated in Figure 10b. Figure 10c gives the output voltage $V_{o}=120 \mathrm{~V}$ and load current under $1 \mathrm{~kW}$ load. Similarly, the measured primary side and secondary side waveforms under $235 \mathrm{~V}$ output and $1 \mathrm{~kW}$ load power are provided in Figure 8 . Since $V_{o}=235 \mathrm{~V}$, the higher gain of the proposed converter under $S_{a c}$ off is needed to regulate load voltage. Therefore, the switching frequency must be decreased and far away from the series resonant frequency. From the test waveforms in Figure 11a, it can be observed that the switching frequency of $v_{a b}$ is about $60 \mathrm{kHz}$. From the test results in Figures 10 and 11, the secondary side diodes are all turned off at zero current switching and the reverse recovery current losses are removed. When load voltage is higher than $240 \mathrm{~V}$, the ac switch $S_{a c}$ is on and the voltage-doubler rectifier topology is adopted on the secondary side. Figure 12 demonstrates the experimental waveforms of the proposed converter under $245 \mathrm{~V}$ output and the rated power. The switching frequency under $245 \mathrm{~V}$ output voltage case is about $96 \mathrm{kHz}$ and the primary side current is close to a sinusoidal waveform. The secondary side diodes $D_{1}$ and $D_{2}$ are all reverse biased and $i_{D 1}=i_{D 2}=0$. Figure 13 gives the experimental waveforms of the proposed 
converter under $V_{o}=360 \mathrm{~V}$ and $P_{o}=1 \mathrm{~kW}$. The switching frequency under $V_{o}=360 \mathrm{~V}$ and $P_{o}=1 \mathrm{~kW}$ cases is about $75 \mathrm{kHz}$ and $D_{1}$ and $D_{2}$ are reverse biased. The higher voltage output in the proposed converter will result in the lower switching frequency to regulate load voltage. Since the input voltage is from the ac-dc converter and controlled at $400 \mathrm{~V}$, the load current variation is investigated. Figure 14 illustrates the measured load voltage and current when $V_{o}=245 \mathrm{~V}$ and $I_{0}$ between $2 \mathrm{~A}$ and $4 \mathrm{~A}$ variation. It is clear to see there is no output voltage variation when load current is changed between $50 \%$ and $100 \%$ rated power. The measured efficiencies of the presented circuit at the rated power are $92.53 \%$, $86.8 \%, 92.9 \%$ and $90.5 \%$ for output voltage $V_{o}=120 \mathrm{~V}, 235 \mathrm{~V}, 245 \mathrm{~V}$ and $360 \mathrm{~V}$, respectively. Due to the switching frequency at $V_{o}=235 \mathrm{~V}$ is lower than the switching frequency at $V_{o}=120 \mathrm{~V}$, there is higher circulating current losses at $V_{o}=235 \mathrm{~V}$ case. Therefore, the circuit efficiency at $235 \mathrm{~V}$ output voltage is lower than the efficiency at $120 \mathrm{~V}$ output voltage under full-bridge rectifier operation. Similarly, the circuit efficiency at $V_{o}=360 \mathrm{~V}$ case is lower than the efficiency at $V_{o}=245 \mathrm{~V}$ case under voltage-doubler rectifier operation.

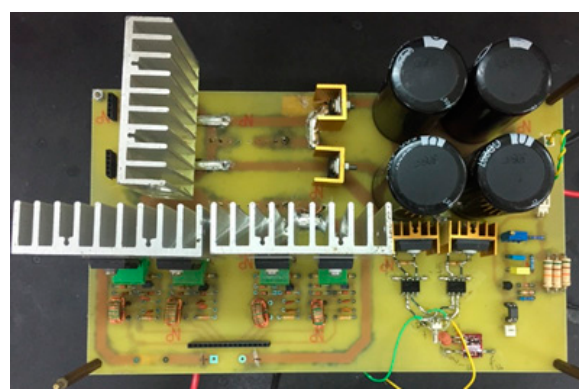

(a)

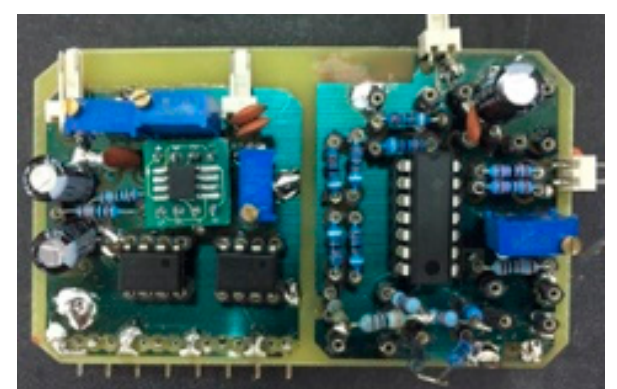

(b)

Figure 8. Pictures of the proposed converter (a) prototype circuit (b) control board.

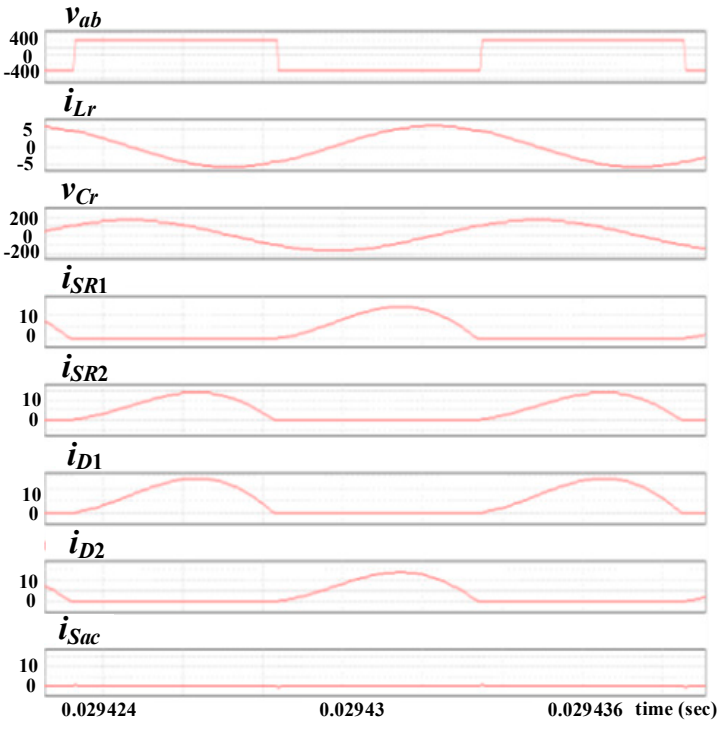

(a)

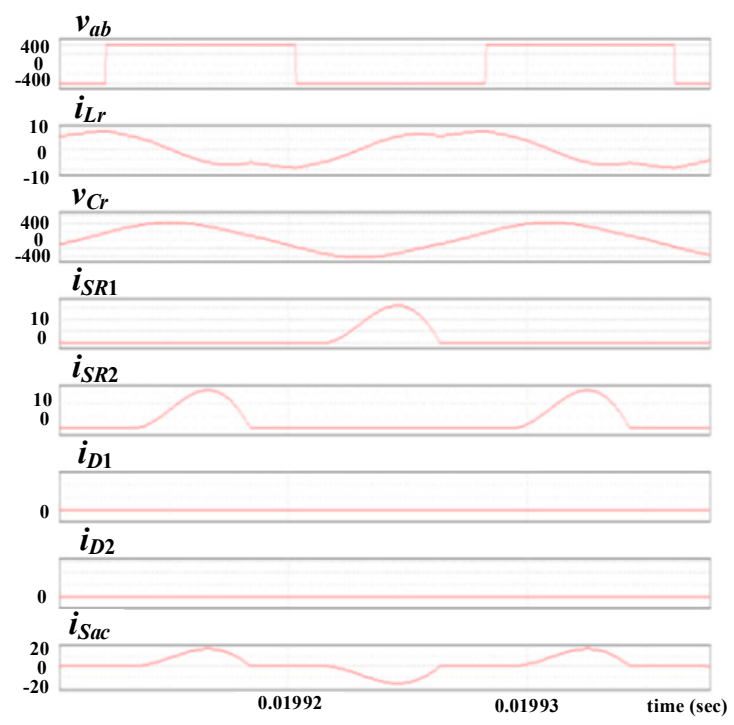

(b)

Figure 9. Simulation waveforms of the proposed converter at the rated power (a) low voltage output $V_{o}=120 \mathrm{~V}(\mathbf{b})$ high voltage output $V_{o}=360 \mathrm{~V}$. 


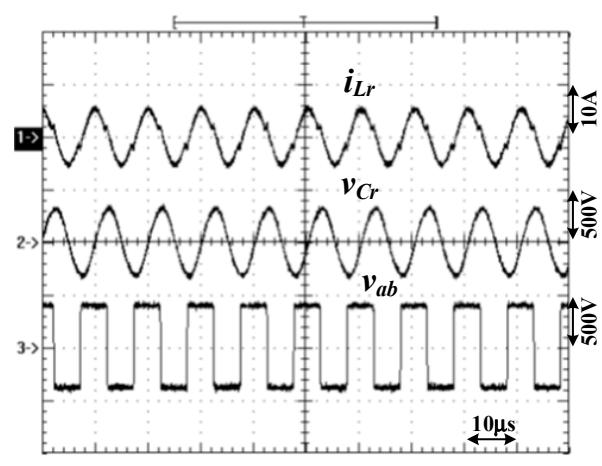

(a)

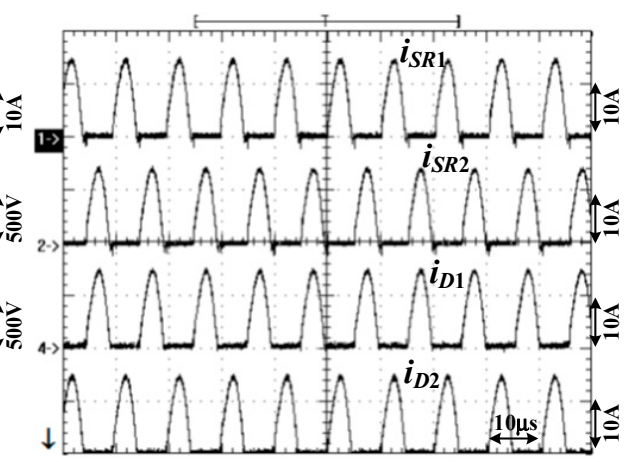

(b)

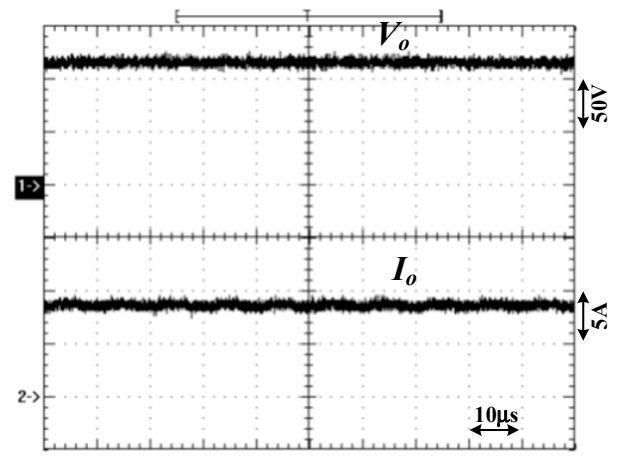

(c)

Figure 10. Measured waveforms of the developed converter under $120 \mathrm{~V}$ output voltage and the rated power (a) the primary side waveforms $i_{L r}, v_{C r}$ and $v_{a b}(\mathbf{b})$ the secondary side currents $i_{S R 1}, i_{S R 2}, i_{D 1}$ and $i_{D 2}(\mathbf{c})$ the load voltage $V_{o}$ and current $I_{\mathrm{o}}$.

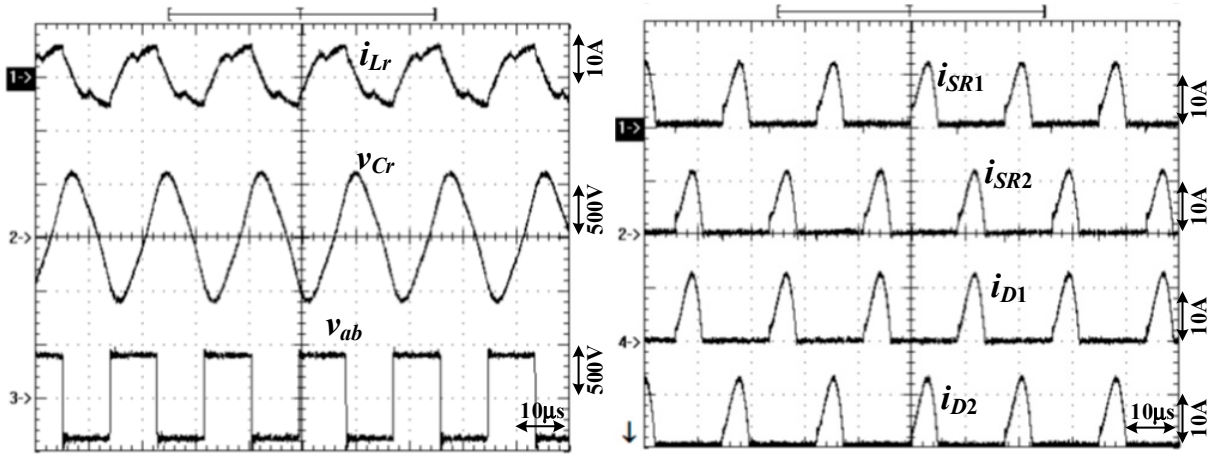

(a)

(b)

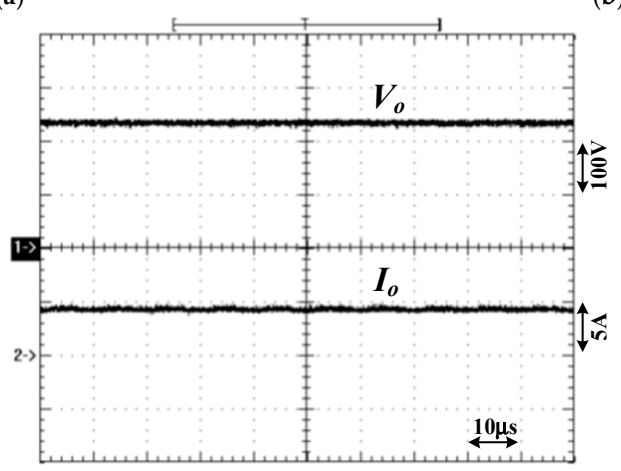

(c)

Figure 11. Measured waveforms of the developed converter under $235 \mathrm{~V}$ output voltage and the rated power (a) the primary side waveforms $i_{L r}, v_{C r}$ and $v_{a b}$ (b) the secondary side currents $i_{S R 1}, i_{S R 2}, i_{D 1}$ and $i_{D 2}(\mathbf{c})$ the load voltage $V_{o}$ and current $I_{\mathrm{o}}$. 


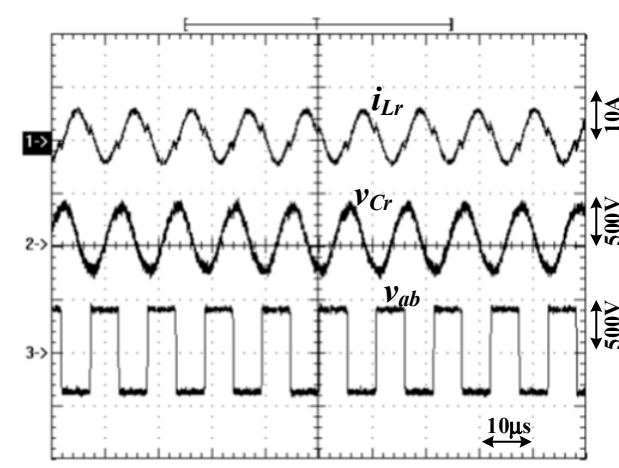

(a)

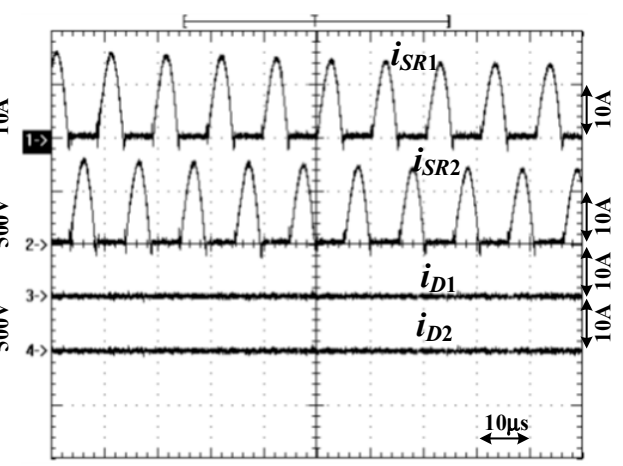

(b)

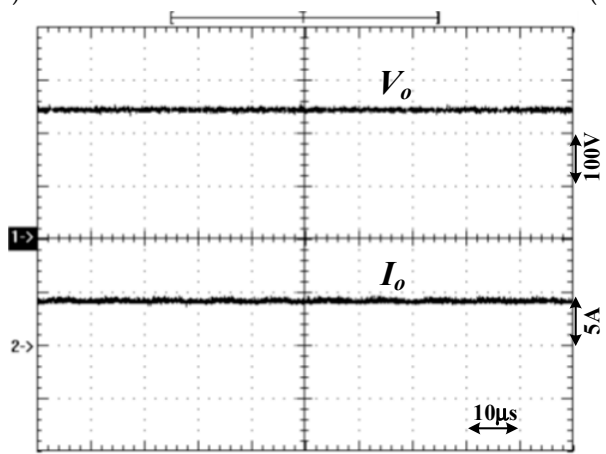

(c)

Figure 12. Measured waveforms of the developed converter under $245 \mathrm{~V}$ output voltage and the rated power (a) the primary side waveforms $i_{L r}, v_{C r}$ and $v_{a b}(\mathbf{b})$ the secondary side currents $i_{S R 1}, i_{S R 2}, i_{D 1}$ and $i_{D 2}(\mathbf{c})$ the load voltage $V_{o}$ and current $I_{\mathrm{O}}$.

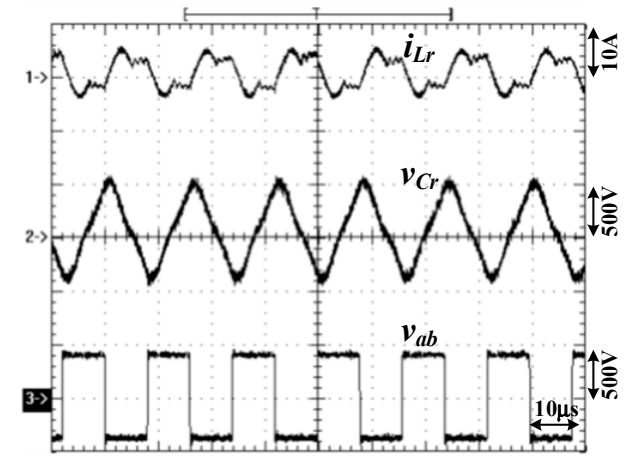

(a)

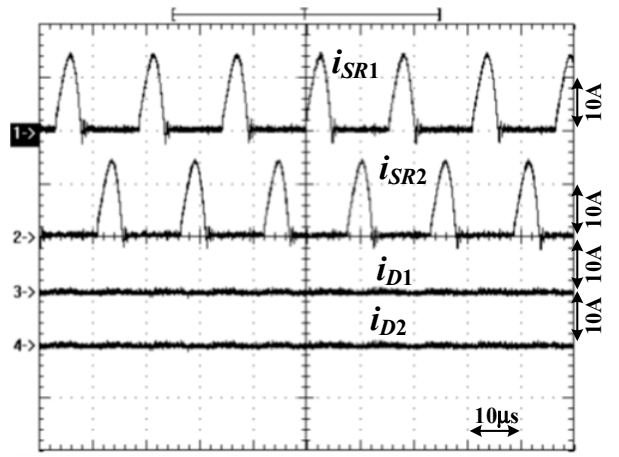

(b)

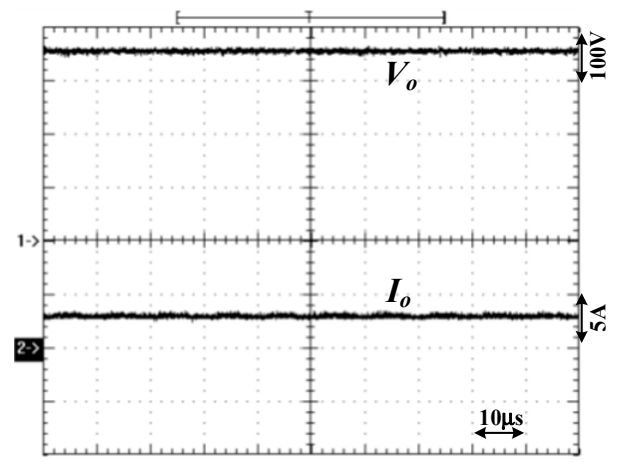

(c)

Figure 13. Measured waveforms of the developed converter under $360 \mathrm{~V}$ output voltage and the rated power (a) the primary side waveforms $i_{L r}, v_{C r}$ and $v_{a b}(\mathbf{b})$ the secondary side currents $i_{S R 1}, i_{S R 2}, i_{D 1}$ and $i_{D 2}(\mathbf{c})$ the load voltage $V_{o}$ and current $I_{\mathrm{O}}$. 


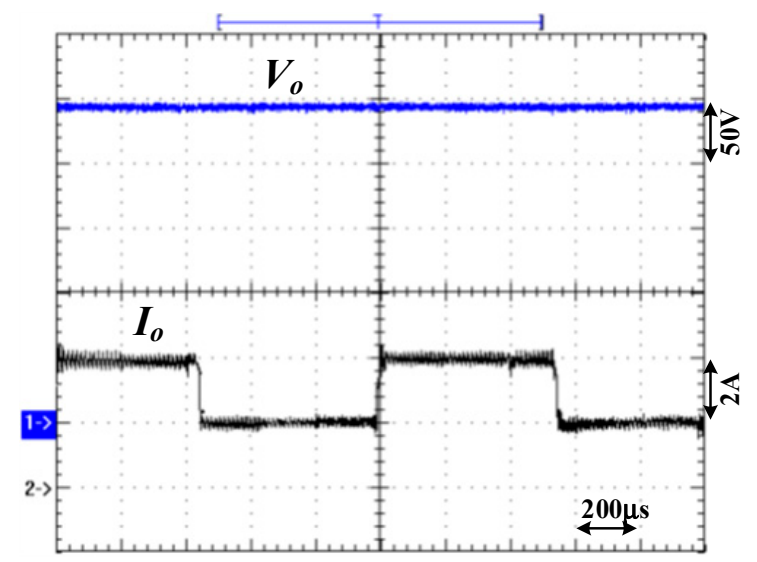

Figure 14. The dynamic response of the proposed circuit under $V_{o}=245 \mathrm{~V}$ and $I_{o}$ between $2 \mathrm{~A}$ (50\% load) and 4 A (100\% load) variation.

\section{Conclusions}

A novel resonant converter with full-bridge rectifier or voltage-doubler rectifier on the secondary side is presented and discussed in this paper for wide output voltage applications such as LED outdoor lighting power units. For wide output voltage demands, the full-bridge rectifier topology or voltage-doubler rectifier topology is selected on the secondary side for lower output voltage range or higher output voltage demand. An ac power switch is adopted in the proposed converter to achieve full-bridge rectifier operation or voltage-doubler rectifier operation. The $L L C$ resonant converter is employed in the proposed circuit and the inductive load of the $L L C$ resonant tank can help the power switches on the primary side to realize soft switching operation and also reduce the electromagnetic interference. Compared to the center-tapped rectifier on conventional wide voltage operation circuit topologies, the voltage rating of the rectifier diodes on the proposed circuit is only one-half of the voltage rating of the center-tapped rectifier. Compared to the conventional hybrid resonant converter [14], the control scheme of the proposed converter is simple by using the analog frequency control integrated circuit with one more hysteresis voltage comparator. The circuit analysis, design considerations and test results are provided to verify the theoretical analysis and demonstrate the performance of the developed circuit for wide output voltage applications.

Author Contributions: B-R.L. designed the main parts of the project and was also responsible for writing the paper. G-H.L. built the prototype circuit and measured experimental waveforms. A.J. provided some technical comments.

Funding: This research is funded by the Mean Well Enterprises Co., Ltd., under Contract 107-284

Conflicts of Interest: The author declares no potential conflict of interest.

\section{References}

1. Kim, J.-W.; Han, J.-K.; Lai, J.-S. APWM adapted half-bridge LLC converter with voltage doubler rectifier for improving light load efficiency. Electron. Lett. 2017, 53, 339-341. [CrossRef]

2. Kanamarlapudi, V.R.K.; Wang, B.; So, L.P.; Wang, Z. Analysis, design, and implementation of an APWM ZVZCS full-bridge DC-DC converter for battery charging in electric vehicles. IEEE Trans. Power Electron. 2017, 32, 6145-6160. [CrossRef]

3. Ali, K.; Das, P.; Panda, S.K. Analysis and design of APWM half-bridge series resonant converter with magnetizing current assisted ZVS. IEEE Trans. Ind. Electron. 2017, 64, 1993-2003. [CrossRef]

4. Lin, B.R.; Chao, C.H. A new ZVS DC/DC converter with three APWM circuits. IEEE Trans. Ind. Electron. 2013, 60, 4351-4358. [CrossRef]

5. Liu, P.J.; Hsu, Y.C.; Hsu, S.R. Drain-voltage balance and phase-shifted PWM control schemes for high-efficiency parallel-string dimmable LED drivers. IEEE Trans. Ind. Electron. 2018, 65, 6168-6176. [CrossRef] 
6. Lee, I.O.; Moon, G.W. Phase-shifted PWM converter with a wide ZVS range and reduced circulating current. IEEE Trans. Power Electron. 2013, 28, 908-919. [CrossRef]

7. Safaee, A.; Jain, P.; Bakhshai, A. A ZVS pulsewidth modulation full-bridge converter with a low-RMS-current resonant auxiliary circuit. IEEE Trans. Power Electron. 2016, 31, 4031-4047. [CrossRef]

8. Pahlevani, M.; Pan, S.; Jain, P. A hybrid phase-shift modulation technique for DC/DC converters with a wide range of operating conditions. IEEE Trans. Ind. Electron. 2016, 63, 7498-7510. [CrossRef]

9. Li, Z.; Wu, T.; Zhang, G.; Yang, R. High modulation method combining variable frequency and double phase-shift for a $10 \mathrm{~kW}$ LLC resonant converter. IET Power Electron. 2018, 11, 2161-2169. [CrossRef]

10. Singh, A.K.; Das, P.; Panda, S.K. Analysis and design of SQR-based high-voltage LLC resonant dc-dc converter. IEEE Trans. Power Electron. 2017, 32, 4466-4481. [CrossRef]

11. Haga, H.; Kurokawa, F. Modulation method of a full-bridge three-level LLC resonant converter for battery charger of electric vehicles. IEEE Trans. Power Electron. 2017, 32, 2498-2507. [CrossRef]

12. Zhang, C.; Gao, Z.; Liao, X. Bidirectional dc-dc converter with series-connected resonant tanks to realize soft switching. IET Power Electron. 2018, 11, 2029-2043. [CrossRef]

13. Sun, W.; Xing, Y.; Wu, H.; Ding, J. Modified high-efficiency LLC converters with two split resonant branches for wide input-voltage range applications. IEEE Trans. Power Electron. 2018, 33, 7867-7870. [CrossRef]

14. Jovanović, M.M.; Irving, B.T. On the fly topology-morphing control efficiency optimization method for LLC resonant converters operating in wide input and/or output-voltage range. IEEE Trans. Power Electron. 2016, 31, 2596-2608. [CrossRef]

(C) 2018 by the authors. Licensee MDPI, Basel, Switzerland. This article is an open access article distributed under the terms and conditions of the Creative Commons Attribution (CC BY) license (http:/ / creativecommons.org/licenses/by/4.0/). 